\title{
SUPREMATISMO Y REVOLUCIÓN. ARTE MODERNO Y POLÍTICA CONTEMPORÁNEA
}

\author{
Juan José Gómez Gutiérrez* \\ jgomez32@us.es
}

RESUMEN Este artículo examina la estética suprematista en relación con teorías politicas contemporáneas sobre la revolución y la transformación social. El punto de partida del suprematismo es la destrucción de la realidad objetiva como acto liberador. Aunque diversos autores contemporáneos del campo de la teoría política conciben el arte tcomo producción de sentimientos que actúan como puntos de partida de la acción y el compromiso. Ambas perspectivas se entrelazan en el concepto de 'revolución': la liberación de la representación totalitaria y la creación de una nueva sociedad.

Palabras clave Estética, Suprematismo, Arte moderno, política, revolución.

ABSTRACT This article discusses suprematist aesthetics in relation to contemporary political theories of revolution and radical social transformation. The starting point of suprematism is the destruction of objective representation of reality, and this is understood as liberation. However, many contemporary authors in the field of political theory understand art as production of feelings which are, in turn, the starting point of action and engagement. Both perspectives are interwoven in the concept of 'revolution': the liberation from totalitarian representation and the creation of a new society.

Keywords Aesthetics, Suprematism, Modern Art, Politics, Revolution.

* Universidad de Sevilla . Artigo recebido em 23/09/2014 e aprovado em 14/05/2015. 


\section{Introducción: del futurismo al suprematismo}

Malevich define el arte como la habilidad de construir "sobre la base del peso, la velocidad y la dirección del movimiento" (Malevich, 1915, p. 181). Los objetos son el estado momentáneo de "una masa de movimientos en el tiempo" (Malevich, 1915, p. 175) y cualquier imagen fija es constitutivamente inestable. Lo permanente es el movimiento activo "que, mediante una multiplicación, genera nuevas formas" (Malevich, 1927, p. 63).

Entre los antecedentes de esta concepción del arte se encuentra la pangeometría del matemático Nikolai Lobachevsky (1792-1856), muy influyente en la vanguardia prerrevolucionaria rusa -en especial la Unión de Jóvenes de San Petersburgo, de la que Malevich formaba parte. ${ }^{1}$ Lobachevsky había postulado que la geometría no se refería al espacio sino a las extensiones en movimiento. El espacio resultaba de la formalización de las relaciones entre extensiones y el tiempo era una creación artificial derivada de la experiencia de su continuo dinamismo.

La pangeometría entró en Malevich en combinación con el futurismo con el que fue igualmente "violada la totalidad de las cosas" (Malevich, 1915, p. 178), proporcionando los puntos de partida teóricos del suprematismo. En su "Manifesto tecnico della letteratura futurista", F.T. Marinetti (1912) afirmaba que el orden sintáctico "natural" de las palabras era en realidad un hábito heredado de Homero y los latinos, ante el cual oponía el movimiento que establecía analogías entre objetos inconexos. El secreto de la emoción artística futurista se encontraba en el impacto sobre la sensibilidad de estas distantes relaciones:

Los escritores se han abandonado hasta ahora a la analogía inmediata [...]. Han comparado por ejemplo un fox-terrier con un purasangre minúsculo. Otros, más avanzados, podrían comparar ese mismo fox-terrier trepidante con una pequeña máquina Morse. Yo lo comparo, sin embargo, al agua hirviendo. Tiene lugar una gradación de analogías cada vez más amplias, donde hay relaciones cada vez más profundas y sólidas, aunque lejanísimas (Marinetti, 1912, p. 1).

Un ejemplo de la aplicación combinada de la pangeometría y la estética futurista son las ilustraciones de Malevich de 1913 para los poemas zaum de Alexei Kruchenykh y Velimir Khlebnikov (зá: detrás, más allá; yм: mente. Textos aparentemente sin significado, estructurados dinámicamente al estilo de las parole in libertà de Marinetti), donde las extensiones interseccionan entre sí y con símbolos matemáticos que Marinetti (1912, p. 1) empleaba en sus poemas para "acentuar ciertos movimientos e indicar su dirección” (Fig. 1). 


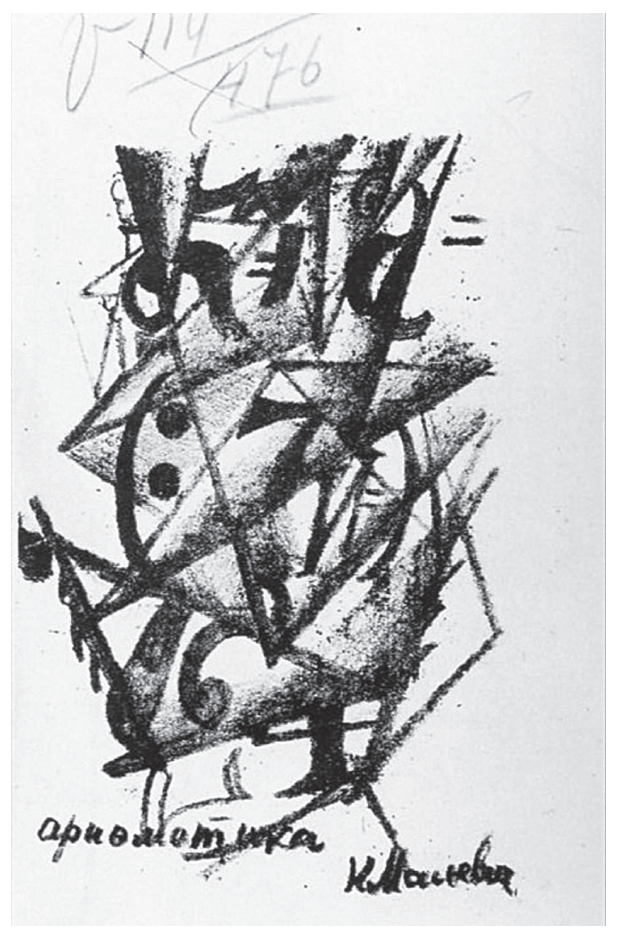

Figura 1: Kasimir Malevich, "Aritmética”, 1913 (Litografía para Refunfuñemos, de Alexei Kruchenykh)

Malevich recibe la influencia de Marinetti en términos "alogicistas". Entiende que el futurismo presenta el orden "natural" de la realidad de los objetos como una configuración contingente, mientras apunta a la necesaria y mutante interconexión entre lo incongruente en el continuo fluir del movimiento. En "Un inglés en Moscú" (1913) (Fig. 2), superpone una serie de objetos inconexos a la figura de un elegante caballero (un pescado, un sable ceremonial, una lámpara de aceite, etc.) combinados con palabras organizadas según la técnica poética futurista, incluyendo la expresión Скаковое общество (sociedad coctel), que también puede traducirse por 'Con una sociedad semejante' tomando ' $\mathrm{C}$ ' como preposición: ( $C$ каковое общество), amenazada por unas tijeras detrás. 'Detrás' о 'más allá' (за) en este caso también puede aludir a la poesía zaum. Час/тич/ное за/тмение es 'eclipse parcial' (las palabras aparecen separadas sin tener en cuenta la división silábica). Incluso si el espectador pretende "leer" "Un inglés en Moscú" siguiendo procedimientos convencionales de asociación entre el 
texto y las imágenes, el resultado ofrece diversas posibilidades y ninguna de ellas definitiva, ${ }^{2}$ lo cual queda subrayado por la metáfora del eclipse, que vuelve a repetirse en "Composición con Mona Lisa" (1914, 'eclipse parcial' частичное затмение). Al mismo tiempo, desaparece de la pintura todo contenido figurativo, a no ser la tachadura de una de las referencias del "gran arte" occidental. "Un inglés en Moscú" y "Composición con Mona Lisa" coinciden en la misma estrategia de manipulación de las convenciones de la representación para subrayar sus deficiencias y plantear así cuestiones nodales de la relación dislocada entre realidad, imagen y palabra.

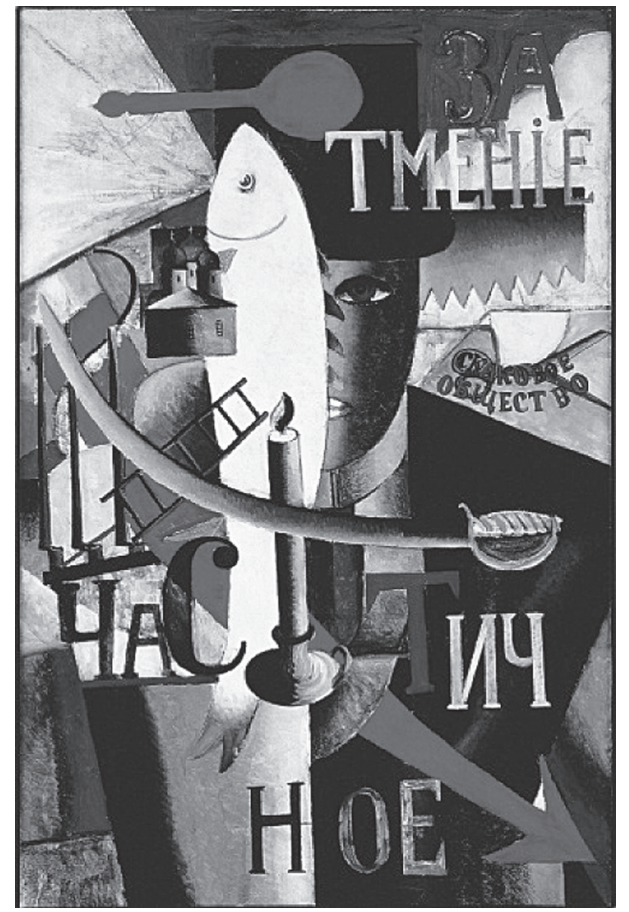

Figura 2: Kasimir Malevich, “Un inglés en Moscú”, 1913 (Stedelijk Museum, Ámsterdam)

Marinetti (1912) concibió su Manifesto della Letteratura recostado sobre un aeroplano. Malevich (1927), también reconoce la visión aérea 
como origen de la percepción suprematista, que destruye la perspectiva convencional basada en la distancia racional y mimética. En este sentido el "Cuadrado negro sobre fondo blanco" (1913, Fig. 3) supone un avance desde la concepción futurista del espacio, situando la figura y el fondo en el mismo plano, con un nuevo ilusionismo antialbertiano. El Lissitzky describió el espacio suprematista como "irracional" y constituido mediante la abolición de la medida de la distancia por la velocidad y la visión aérea. El espacio pasaba a depender de la intensidad y la situación de los planos de color, dando lugar a un sistema posicional donde la pirámide visual se extendía ambiguamente hacia el infinito o hacia el 0: "el suprematismo ha barrido la ilusión del espacio tridimensional sobre el plano, reemplazándola por la ilusión última del espacio irracional con atributos de extensibilidad infinita en profundidades hacia afuera" (Lissitzky, 1925, p. 319). Pero el "Cuadrado negro", en opinión de Lissitzky, aún presupone un orden jerárquico entre la figura y el fondo expresado mediante el contraste cromático. En los "Cuatro cuadrados" de 1915 (Fig. 4), Malevich aplica el blanco de forma completamente diferente y consuma la desaparición de todo ilusionismo, el establecimiento del espacio suprematista a partir de la pura relación de elementos pictóricos. ${ }^{3}$ Y en "Composición suprematista. Blanco sobre blanco", la desaparición del espacio implica la desaparición del objeto. El blanco ya no es un color. Es el espectro completo como límite de lo representable.

Figura 3: Kasimir Malevich, "Cuadrado negro sobre fondo blanco", 1913 (Galería Tretyakov, San Petersburgo) 


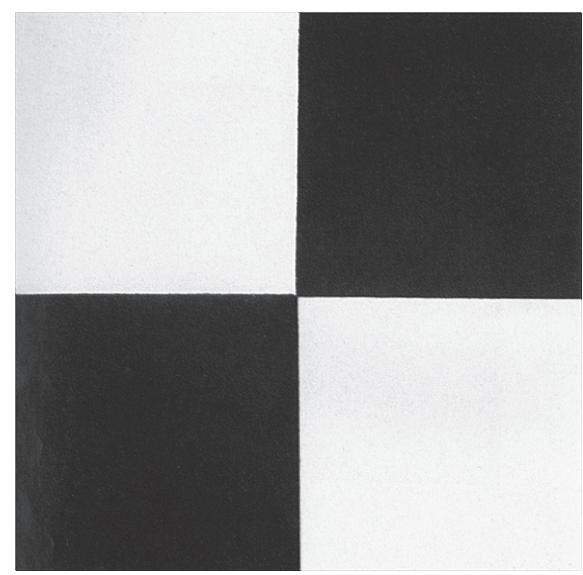

Figura 4: Kasimir Malevich, "Cuatro cuadrados", 1915 (Museo Estatal Radischev, Sarátov)

Jean Claude Marcadé ha subrayado la influencia decisiva de Marinetti sobre Malevich. Aunque, en su opinión, "todo lo que Malevich toma prestado, consciente o inconscientemente, es integrado en una filosofía completamente nueva" (Marcadé, 2003, p. 38). Más que una completa novedad respecto a Marinetti, el suprematismo quizá sea su conclusión a partir de una estética del movimiento que aún posee una densidad objetiva en el futurismo italiano (la glorificación de la máquina y la guerra) de la que termina por despojarse en Malevich para hacerse pura destrucción, pura negatividad. Malevich emplea los elementos de sus cuadros del mismo modo que el poema futurista es una composición de significantes arbitrarios en permutaciones variables. Ello deriva en un sistema autorreferencial que no comunica ideas, o presenta modelos abstraídos de visiones históricas del mundo, sino sensaciones sin conceptos separadas de la facultad intelectual: "el futurista no debe de ningún modo retratar la máquina, sino crear nuevas formas abstractas" (Malevich, 1927, p. 63). Así tiene lugar el tránsito del realismo convencional (aunque fuese el de la sociedad industrial) a la exposición del problema de la representación artística mediante el cuestionamiento del arte mimético.

\section{La historia del arte como conflicto y sucesión de elementos adicionales}

Malevich entiende por elemento adicional una categoría normativa que asegura la estabilidad de los elementos dinámicos (accidentales) en la 
interacción del sujeto con el mundo. "Esa 'inclusión-en-la-armonía' de los elementos dinámicos (es decir, su sistematización) significa una transformación de lo dinámico en estático" (Malevich, 1927, p. 7). El elemento adicional da lugar a un sistema que crea y mantiene el orden. Todo lo que se halla fuera de la normalidad es excluido por considerarse una amenaza para la norma y ese elemento excluido es el nuevo elemento adicional, que produce nuevas normas contra la norma vigente.

En el arte, el elemento adicional se refiere al modo histórico y determinado en el que se expresa la relación entre la subjetividad y el fenómeno motivador (objetivo) de la representación. Es posible reconocerlo a partir de sus características formales. Define, además, un estilo como lo común que regula la serie histórica de obras que lo conforman. Es el factor estructurarte de la producción y de la experiencia estética, y da cuenta de la obra de arte en relación con su momento histórico: "dado que esta relación puede darse de modos diversos, lo más provechoso es clasificar sus formas de aparición similares según categorías, reconocer posibles variables pictóricas dentro de cada categoría y representar estas variables mediante una fórmula gráfica" (Malevich, 1927, p. 36). Ello ofrece un método científico a la historia del arte, pues cada modo de la relación corresponde a un estado específico de la cultura artística en un periodo determinado. "Para el investigador, una pintura es un documento de proporciones formales y cromáticas, reconocibles en su estructura y en su factura" (Malevich, 1927, p. 38).

La hegemonía de un elemento adicional, su reconocimiento social como factor determinante del modo objetivo de representación, depende en gran medida de su capacidad de definir históricamente la norma de la visión y el orden de lo real. Cuando aparece una obra de arte con un elemento adicional distinto, tiene lugar una alteración "revolucionaria" de ese orden estable. Así que, tomada en conjunto, la historia del arte consiste en una sucesión dialéctica de estilos donde el orden estético de lo reconocible, que se ha generalizado como regla de la percepción, se ve amenazado constantemente por un nuevo elemento adicional antagónico.

"La lucha entre el artista activo y la sociedad indolente es un estado crónico e inevitable" (Malevich, 1927, p. 34). Lo permanente es el conflicto de elementos normativos en términos políticos o de poder, "por lo que la sociedad se apresta a aislar a los artistas que crean según el sentido de esta norma nueva y a su arte" (Malevich, 1927, p. 8). Aunque la inmanencia entre las características formales e históricas del elemento adicional implica la potencial reversibilidad de sus relaciones de preeminencia o marginalidad. Es decir: el modo objetivo de representación en relación a un elemento adicional 
tiene lugar bajo una modalidad temporal o de despliegue histórico. Pero, en cada momento y en la sucesión histórica, lo decisivo es el proceso de identificación o desidentificación del artista y la sociedad con ese modo contingente de representación y la objetividad que representa. Todo elemento adicional aspira a constituirse en fundamento incondicionado de la experiencia, dar lugar a una totalidad sistemática, a la identidad entre objetividad y representación. Pero "nada escapa a la temporalidad — como escribía Malevich en su lecho de muerte - y esa era la idea de mi elemento adicional" (Malevich \& Moraza, 1935, p. 83). Así apunta precisamente al cortocircuito constitutivo entre representación y realidad como condición de posibilidad de la historia del arte y, al mismo tiempo, de la pervivencia del arte a través de la historia.

\subsection{Historia y estética suprematista}

Si el suprematismo es el arte de la sensación pura, liberada de todo contenido objetivo, ${ }^{4}$ la idea suprematista de historia del arte es esencialmente teleológica en el sentido greemberguiano, de historia de la depuración de lo extra artístico hacia la abstracción. ${ }^{5}$ Esa concepción, que sitúa cada estilo en la cima del desarrollo histórico, viene definida por lo que Arthur Danto (2010) llama la 'Era de los manifiestos' característica de las primeras vanguardias, donde cada movimiento artístico implica la superación y la anulación del anterior. Pero a esta superpone Malevich un concepto general del arte difícil de reducir a la clasificación de Danto, ya que el hecho de integrar las imágenes suprematistas en la categoría de arte implica presentarlas junto a otras imágenes históricas objetivas y así permite la comparación y la unificación de ambas. Danto presenta a Malevich como ejemplo supremo, guiado por "certezas cuasi religiosas", de la fe en el arte como "vehículo de trasformación espiritual" (Danto, 1994, p. 172) lo cual, combinado con la tesis de Greemberg, acaba por definirlo como esencialmente moderno. Excede de los propósitos de este trabajo comentar en detalle sus apreciaciones, pero es de considerar que quizá Malevich, el autoproclamado "campeón de la ironía" (Malevich \& Moraza, 1935 , p. 74) careciese de tal densidad teológica y emplease en ocasiones las alusiones religiosas —incluyendo la colocación del "Cuadrado negro" en una esquina superior de la habitación, el lugar destinado a los iconos $\operatorname{ortodoxos}^{6}$ —de forma más superficial. A la manera irreverente y burlesca de la vanguardia prerrevolucionaria rusa y en consonancia con el combate 
contra el pasatismo inaugurado por Marinetti en 1914. Es decir, como un modo de provocar, ridiculizar y escandalizar. El matiz es importante porque, descargando al suprematismo de teología o al menos no exagerando sobre "el esfuerzo místico de abandonar el mundo finito y entrar en la unidad con el Uno", la pretensión de Malevich de pintar "con la mayor expresividad y según las leyes del arte" (Danto, 1994, p. 176) que Danto le reconoce puede leerse de un modo diferente y según su afirmación de que "el arte hoy es solo arte" (Danto, 1994, p. 172) y ha desertado de las grandes verdades. Por eso la gaya ligereza de las imágenes suprematistas no son un añadido que, según Danto, oculta su profundidad teológica, sino el resultado consecuente de esta práctica. Los constructivistas y LEF, educados por Malevich en Vitevsk, son ejemplo de lo contrario. El diseñador y el realista socialista lo son porque su libre elección tiene lugar mediante la adhesión a una certeza.

La teoría del elemento adicional supone un principio para la historización y la progresión de los estilos. Pero el elemento adicional también se introduce en la historia del arte de manera horizontal, como si fuese una enfermedad, la "infección de un bacilo" (Malevich, 1927). ${ }^{7}$ En la estética de la mutabilidad, el 'bacilo suprematista' que infecta la historia del arte es, por una parte, un hecho histórico y, por otra, apunta al fallo constitutivo en capturar lo real con su representación que es, precisamente, la condición para la sucesión de elementos adicionales. Desde este punto de vista, el arte de la sensación pura no es un nuevo arte, sino que toda obra es suprematista en tanto que su valor como arte depende de la representación de la sensación pura de no objetividad que antecede al contenido objetivo. Por eso Boris Groys afirma que no es posible escapar del cuadrado negro, ni tampoco parece operar en el suprematismo procedimiento alguno de exclusión o superación del arte pasado. "Cualquier imagen que vemos es, simultáneamente, el cuadrado negro” (Groys, 2010, p. 6). También lo son las del periodo postsuprematista de Malevich incluyendo el retorno a la pintura figurativa de resonancia renacentista en el Autorretrato de 1933 que provocaba la perplejidad de Danto (1994) y aparece firmado por El cuadrado negro (Fig. 5). 


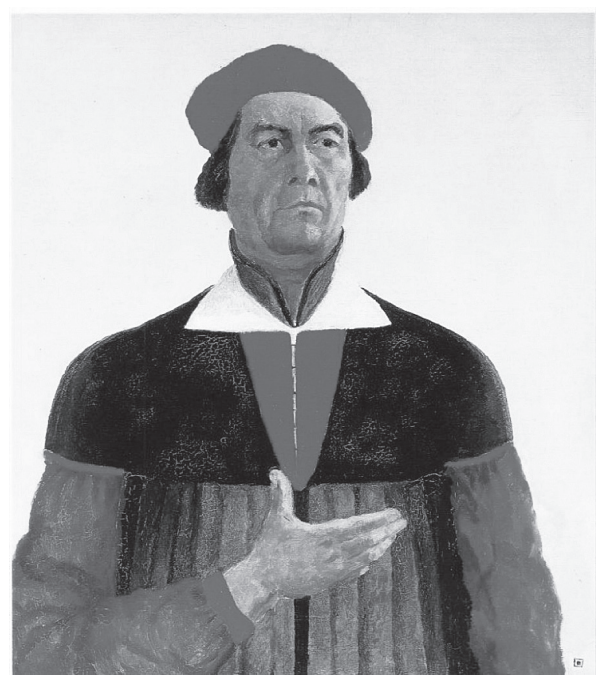

Figura 5: Kasimir Malevich, "Autorretrato”, 1933 (Museo Estatal Ruso, San Petersburgo. Pequeño Cuadrado negro a modo de firma en la parte inferior derecha)

Esther Levinger (2005), ha conectado la concepción de la experiencia estética en términos de shock por la aparición de un nuevo elemento adicional con el concepto de 'extrañamiento' (остранение, introducido por Viktor Shklovsky en su ensayo "Arte como técnica" de 1917). Lo determinante en la sensación suprematista de no objetividad es la disfunción causada por la aparición de un elemento adicional alternativo como consecuencia de la disociación del signo y el referente. El extrañamiento contrarresta las expectativas miméticas del espectador. Muestra que, "en el mundo de lo objetivo, nada es tan 'firme e inconmovible' como nos lo imaginamos en nuestra conciencia. En ella, no reconocemos nada a priori, nada construido para toda la eternidad. Todo lo 'arraigado', todo lo cotidiano puede ser llevado hacia un nuevo orden (que, en primera instancia, no será cotidiano)" (Malevich, 1927, p. 90). Este descubrimiento supone el paso del futurismo al suprematismo: que "la belleza de la velocidad es eterna" (Malevich, 1915, p. 176), eterno el movimiento de destrucción.

\section{El arte no objetivo. Nuevo realismo pictórico}

La representación se liga a los límites históricos en los que se formula, margina o borra lo real. Pero, además, la aparición autónoma de un nuevo 
elemento adicional implica la subversión de esos mismos límites. Lo real objetivo se estructura de manera ambigua entre la identidad y la representación; pero lo real que precede a su aparición a la conciencia como su representación histórica objetiva es solo un eclipse, una sombra o un vacío que la representación intenta llenar en vano. Significa la división antagonista que no se puede representar completamente.

La relación entre lo real y su representación incompleta no solo está en prácticas artísticas que se suceden en la historia fracasando en representarlo. Siempre permanece lo anti histórico no objetivo: la desidentificación que inicia la competición de elementos adicionales, el extrañamiento que es de hecho inherente a la historia del arte, no su límite exterior; pero por esa precisa razón no se puede representar objetivamente. La paradoja está en que lo real, la sensación de no objetividad excluida de la representación, es una representación que elude la representación. Es, precisamente, lo real como punto de fallo de la representación, el 'nuevo realismo pictórico' (Malevich, 1915, p. 173) donde el arte gana el espacio de la autonomía.

Solo la destrucción sobrevive a la destrucción en el constante movimiento. No obstante esa destrucción es solo su traza visible, su representación. Si, en la Exposición 0-10, Malevich colocó el cuadrado negro en el lugar de los iconos, en palabras de Groys "la muerte de Dios significa que ninguna imagen puede estabilizarse infinitamente — pero también significa que ninguna imagen puede ser totalmente destruida" (Groys, 2013, p. 4). Malevich lleva a cabo la inversión de la relación entre lo formal y lo material en el arte. Proclama la destrucción artística de todas las certezas y la indestructibilidad del arte al mismo tiempo; de la realidad material que aparece a la conciencia en toda su materialidad sensible no objetiva, "cuando liberamos nuestro arte del tema vulgar y enseñamos a nuestra conciencia a ver todo en la naturaleza, no como formas reales y objetos, sino como masas materiales de las que deben hacerse las formas, que no tienen nada que ver con la naturaleza" (Malevich, 1915, p. 175).

El problema del arte en Malevich es el problema de representar el problema de la representación. "El cuadrado negro permanece opaco porque la materia es opaca" (Groys, 2013, p. 6). No es un objeto, es un eclipse. En su último párrafo escrito en el lecho de muerte, Malevich pide ser enterrado "frente a la tierra; de espaldas al sol; que sea ella mi eclipse, [...] pero también para ser yo la razón de otro eclipse para la tierra. Y seré así quien bajo la tierra oculte el sol. Mi última victoria. Y a mi espalda, mi última firma, el último cuadrado negro, la parte visible de mi tumba" (Malevich \& Moraza, 1935, p. 86). 


\section{Suprematismo y revolución}

La teoría del elemento adicional plantea la historia del arte como conflicto entre principios de las lógicas de los estilos que actúan como condición de posibilidad de una norma o aspiran a sustituirla. Cuando aparece un elemento adicional contrario al establecido que se tiene por "natural", el ideal del nuevo elemento adicional es también su legitimidad como sensación "natural" u objetiva. Lo que persiste en la sucesión de estilos, es decir: la norma junto a la destrucción de la norma. El elemento adicional es funcional a su poder regulador. Todo intento de fundamentar racionalmente cualquier elemento adicional conduce a su deslegitimación. Por otra parte, todo elemento adicional obtiene su justificación apareciendo a la sensibilidad como modo absoluto de representación de la realidad. Por ello la relación entre elemento adicional y obra de arte da lugar a un sistema autocontenido. Solo puede resistir a la crítica racional aquello fundamentado en el ocultamiento del vacío, de la sensación de no objetividad. Es lo que Malevich llama 'arte del salvaje': "la reflexión, como en un espejo, de la naturaleza sobre el lienzo" (Malevich, 1920, p. 293). En el 'arte del salvaje', las sensaciones no objetivas son representadas por el contenido objetivo hasta el punto de la confusión entre ambos.

Cuando, en el año 1913, inmerso en mi desalentadora pretensión de liberar al arte del lastre de lo objetivo, busqué la evasión en la forma del cuadrado y colgué en una exposición un lienzo en el cual sólo se veía representado un cuadrado negro sobre fondo blanco, la crítica, y con ella la sociedad, suspiraron desasosegadas: 'Todo aquello que siempre hemos amado se ha perdido: estamos en un desierto... ¡t tenemos ante nosotros un cuadrado negro sobre fondo blanco!' [...] A la crítica y la sociedad, aquel cuadrado les pareció algo incomprensible y peligroso (Malevich, 1927, pp. 70-71).

Groys afirma que la vanguardia es impopular "precisamente porque es democrática, y si fuese popular, no sería democrática" (Groys, 2010 p. 9). La impopularidad del cuadrado negro se debe a aparecer en un contexto dominado por la ligazón afectiva con lo objetivo como modo "totalitario" de experiencia estética. La anulación de la sensación no objetiva. En este sentido, el Cuadrado negro de la Exposición 0-10 supone una reivindicación democrática en un mundo que no lo es. Por lo demás, la bofetada de Malevich al bienpensantismo pequeñoburgués podía parecer revolucionaria en 1913. Aunque, en 1917, la misma bofetada podría entenderse fácilmente como contrarrevolución, como un acto de desestabilización de los logros revolucionarios, mientras la consolidación de la revolución exige revivir las normas de orden y estabilidad.

Dado que, en última instancia, todo elemento adicional es irracional, la expresión de una sensación, Malevich termina por convertir la historia del 
arte en propaganda; en una sucesión de elementos adicionales antagónicos que, por otra parte, perpetuán la misma dialéctica de poder. En estos términos tiene lugar su indiferencia ante el arte soviético de vanguardia, centrado, como declaraba el Programa del grupo LEF en "reforzar las conquistas de la Revolución" (LEF, 1923, p. 8). LEF intentaba sortear la paradoja futurista y suprematista recurriendo al salto histórico que significaba Octubre. Antes, las “estrofas-látigo, las líneas espina”. Después, "Octubre terminó de limpiar, dio forma, organizó. El futurismo se convirtió en el frente izquierdista del arte. Nos convertimos en 'nosotros'. [...] Junto con el trabajo de organización, dimos a luz los primeros objetos artísticos de la nueva época nacida en Octubre". Todo ello consistía en dedicarse "a las tareas de agitación artística exigidas por la revolución” (LEF, 1923, pp. 14-15).

Por ejemplo, en la serie o cómic suprematista-constructivista de Lissitzky "Historia de dos cuadrados" (Fig. 6), el cuadrado abandona su condición no objetiva para aparecer como protagonista de una narrativa épica que desemboca en la victoria del rojo, desplegándose a través de una secuencia precisa de imágenes mientras se carga gradualmente de contenido semántico.

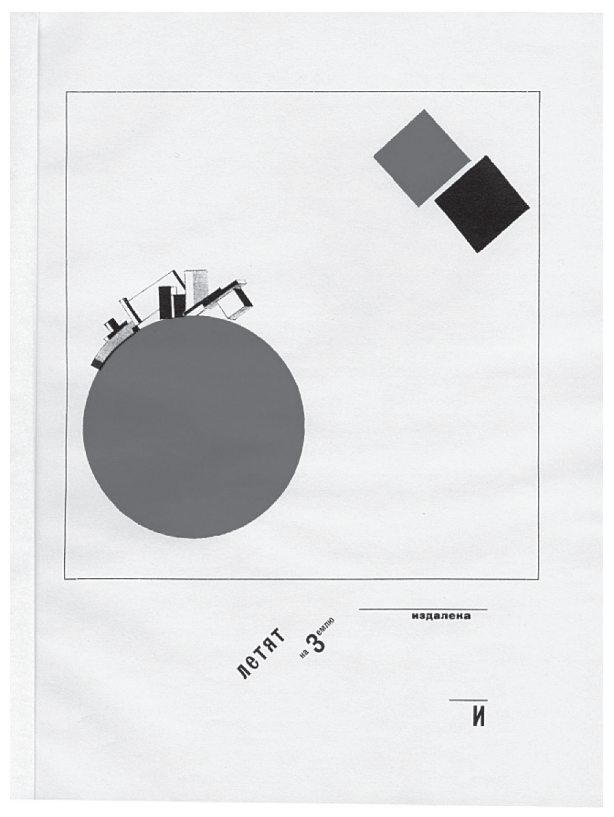

Figura 6: El Lissitzky, "Volando hacia la tierra desde la distancia" (en: Historia de dos cuadrados, Moscú: Unovis, 1920, Museum of Modern Art, Nueva York) 
Lissitzky tiende al reforzamiento de la identidad del cuadrado rojo desde que busca otorgarle un sentido objetivo. El cuadrado de Malevich plantea la falta de sentido instalada en toda objetividad, en lugar de revertir relaciones de poder. Para él, la incongruencia es el espacio de la libertad. Como escribe Marcadé, "el suprematismo no es una filosofía de la negación en un proceso dialéctico; es una filosofía del 'sin', de la ausencia” (Marcadé, 2003, p. 40). La revolución suprematista es pura revuelta sin teoría, programa u objetivo. Es pura liberación. Se despliega frente al poder para destruirlo, no para sustituirlo por un nuevo poder - lo cual solo resultaría en una operación de legitimación de ese poder: "para Malevich, transformar las formas en cero es solo un trampolín para ir más allá del cero en las regiones de la nada liberada" (Marcadé, 2003, p. 41).

\section{Gran arte y estética de la política}

El elemento adicional se desarrolla en un leguaje preexistente, histórico, incorporando un componente retórico (la sensación objetiva) que opera como clave del proceso de identificación social entre la realidad y su representación políticamente activa. Cuando Antonio Gramsci $(1929-1935,1975)$ teoriza la hegemonía en los "Cuadernos de la cárcel”, llama 'materialismo vulgar' al error epistemológico derivado del ocultamiento de este componente retórico. Luciano Gruppi (1978, p. 22) interpreta este término como pasión ante la aparición a la conciencia de un particular como pura universalidad no mediada: "la voluntad real se disfraza de acto de fe en cierta racionalidad de la historia, en una forma empírica y primitiva de finalismo apasionado."

Sin embargo, en desarrollos actuales a partir de la hegemonía de Gramsci, en el ámbito de la teoría política radical, el elemento decisivo es de naturaleza retórica, es decir: la retórica es la condición para que la realidad vacía y dislocada adquiera una coherencia formal que posibilite la acción política. Ernesto Laclau, por ejemplo, afirma que "la completud de la sociedad es un objeto imposible que sucesivos contenidos contingentes intentan personalizar mediante desplazamientos catacrésicos" (Laclau, in Butler, Laclau, Žižek, 2000 , p. 82) y la recomposición de la diferencia, de que lo que carece de nombre solo se puede enunciar metafóricamente. Laclau termina definiendo lo ético como "inversión" sentimental en un escenario particular mediado por la autoconciencia de la diferencia entre norma vigente y acción autónoma que al tener lugar reclama el reconocimiento social. El acto ético-político es por lo demás histórico, basado "en la articulación de prácticas estéticas sedimentadas 
que nunca desaparecen hasta el punto de requerir un acto de refundación total" (Laclau, in Butler, Laclau, Žižek, 2000, p. 82).

Alberto Toscano (2009) filia a Antonio Negri con Alain Badiou en la generación de pensadores revolucionarios que fue capaz de sobrevivir a la ola 'neocon' de los ochenta, que eran tiempos de derrota de la izquierda y aparente despolitización de la actividad intelectual. Algunos ámbitos artísticos de entonces - Toscano cita la revista milanesa "A/Traverso" de Franco Berardi - se constituyeron como espacios de resistencia desesperada $\mathrm{y}$, al mismo tiempo, de germen de transformación.

Según la explicación de Toscano, Negri entiende el arte como una abstracción periodizada del trabajo y este a su vez como modo de objetivación de la creatividad humana. Es inseparable de la ética y la política y se configura en la historia de manera determinada, de acuerdo con una narrativa de liberación del trabajo instrumental: "la irreconciliable dialéctica entre autonomía política y estética [...] es abolida por Negri en favor de un tipo de autorregulación ontológica (o autovalorización) del trabajo vivo" (Toscano, 2009, p. 381). En definitiva, la experiencia estética consiste en la presentación ante la intuición y el sentimiento de la pasión por la transformación encarnada en el trabajo. Y la producción artística y la experimentación remiten a "ese acto creativo que constituye el trabajo en su esencia original" (Negri, citado en Toscano 2009, p. 375).

En sus “15 tesis sobre el arte contemporáneo", Badiou llama 'arte imperial' a lo que acota el ámbito de lo efectivamente visible o de lo que es posible ver. Se pregunta si la creación artística consiste en realizar o apercibirse de una posibilidad, de representar la posibilidad, o bien crear una posibilidad, algo posible que antes no lo era: "La gran función del arte hoy es la creación de una posibilidad. En otras actividades de circulación, comunicación, el mercado, etc. tenemos siempre la realización de posibilidades, la infinita realización de posibilidades. Pero no la creación de una posibilidad. Y así es también una cuestión política, porque la política realmente significa la creación de una posibilidad" (Badiou, 2003, p. 3).

Es fácil notar la semejanza de la noción de 'arte imperial' de Badiou con la teoría del elemento adicional. También aquí, el arte presenta a la sensibilidad un nuevo principio estructurante incondicionado alternativo de comunidad y de relación humana con el mundo. Si el "sentido común de la libertad" supone la acción y la elección en el campo de lo posible, lógicamente congruente, la nueva posibilidad inaugura más bien una nueva lógica y por tanto un nuevo concepto de libertad. La creación concreta ante la sensibilidad de "una nueva forma de libertad" (Badiou, 2003, p. 4) opera del mismo modo en que 
el elemento adicional alternativo redefine la forma de percibir y el propio sentido de lo objetivo; pero no pone en cuestión el poder de lo objetivo como tal. Sin embargo en Malevich el suprematismo no solo implica un elemento adicional sino también una práctica artística marcada por la problematicidad de la relación entre elemento adicional y verdad. Aquí aparece una diferencia fundamental con Badiou, que en ningún momento cuestiona la relación arteverdad y, antes bien, toma el arte, desde la perspectiva de la filosofía, como verdad inmanente y singular. ${ }^{8}$ Por esta circunstancia, Fabián Ludueña afirma en su introducción al "Pequeño manual de inestética" que "bajo el signo lógico-ontológico de la verdad, Badiou reconduce la estética al cauce de lo verdadero y de lo falso y de este modo parecería imposible liberarla del todo de las determinaciones teológicas" (Ludueña en Badiou, 2009, p. 33). Como alternativa, Ludueña propone una naturaleza "fantasmal" para los objetos estéticos que "si bien son captados netamente por los sentidos, parte de su existencia se haya fuera de la metafísica del ser" aunque más bien en forma de un desvanecerse que de un ser (Ludueña en Badiou, 2009, p. 37). Se trata de una apreciación de la máxima importancia para establecer la diferencia entre el concepto de revolución suprematista y el que maneja Badiou, incluyendo el papel que el arte tiene en ella. Badiou busca en la verdad un principio firme de la política y parece entender que ese principio es estético. El efecto del cuadrado negro es el contrario: el de la desrealización de lo que se tiene como cierto. El shock. El arte como eclipse no es verdad ni crea posibilidades. Más bien abandona a su suerte a la filosofía que, como efecto secundario, al ser despojada de sus verdades inmanentes y singulares aparece escuálida e incapaz. Malevich afirma la libertad que no aspira a fundar un orden de lo posible, sino que habita en la inconsistencia de una sombra: "Todo aquello que siempre hemos amado se ha perdido: estamos en un desierto... ¡tenemos ante nosotros un cuadrado negro sobre fondo blanco!" (Malevich, 1927, pp. 70-71).

\section{Conclusión}

En Laclau, Negri y Badiou, persiste la misma concepción de la pasión, la emoción o la retórica como condición de posibilidad de la acción éticopolítica: "si el momento ético se relaciona inicialmente con la presencia de símbolos vacíos en la comunidad, la comunidad requiere la producción 
constante de esos símbolos para que sea posible una vida ética" (Laclau, in Butler, Laclau, Žižek, 2000, p. 85). Como LEF, parecen resolver el problema de la imposibilidad a priori del acto ético-político involucrando al arte en un retorno a esa "forma empírica de finalismo apasionado", criticada por Gramsci, y ante la cual Malevich desplegaba su espléndida indiferencia revolucionaria: la inversión estética en algún tipo de orden normativo que dé lugar a una decisión, que suponga un desplazamiento del objeto imposible de la inversión ético-política, a la cual substituye retóricamente para enfrentarse al orden normativo establecido y prevalecer sobre él. La sustitución retórica del objeto de la acción se proyecta en un arte de valor cultural, civilizatorio: un arte militante que, por emplear las expresiones de Gramsci "lucha por una nueva cultura, un nuevo humanismo, un fervor apasionado" (Gramsci, 19291935, 1975, p. 426), donde el elemento técnico va estrechamente ligado al interés político y moral como su modo de transmisión al conjunto social. Para Gramsci, aquí se encuentra el origen de todas las demandas de politización del arte: "el político imagina el hombre como es y, al mismo tiempo, como debería ser para alcanzar un fin determinado. [...] El artista representa necesariamente 'aquello que es' en un cierto momento, personal, no conformista, [...]. Por eso, desde el punto de vista político, el político nunca estará contento con el artista ni podrá estarlo" (Gramsci, 1929-1935 -compilación de 1954-, p. 13). A no ser, por supuesto, que se preste a dotar un contenido determinado de una forma políticamente activa.

El poder estructurante y motivador de la acción, la norma, aparece como intuición estética y esta a su vez como la verdad de la razón. Sin embargo, definir al sujeto por la acción no contrarresta los efectos del poder regulador escondido tras esas prácticas. Cuando Laclau afirma que "semejante contextualización radical del orden normativo/descriptivo solo ha sido posible por la descontextualización radical introducida por el momento ético" (Laclau, in Butler, Laclau, Žižek, 2000, p. 70), opera el mismo concepto de revolución que LEF, basado en la dialéctica de destrucción de lo viejo para la construcción de lo nuevo, una dialéctica del poder que subyuga la materialidad no objetiva de la realidad, sometiendo la estética a la norma.

Malevich vive más bien la revolución como dislocación entre signo y significado. Como falta de medida y valor que se transforma en lo contrario a la impotencia ética por el mero hecho de su exposición pública. En su lecho de muerte, recordaba a Cimabue, cuya noción de espacio es negativa, solo la de 
la relación entre elementos. ${ }^{9}$ Una influencia perceptible en sus composiciones suprematistas (Fig.7). Su manifiesto sobre el nuevo realismo de 1915 contiene una consigna estética-política: "hay que dar vida a las formas y el derecho a la existencia individual" (Malevich, 1915, p. 175). La ausencia de norma cierta. El paso de una abstracción normativa a la abstracción concreta de la comunidad de singularidades autónomas liberadas de su justificación racional, que establecen asociaciones abiertas y libres.

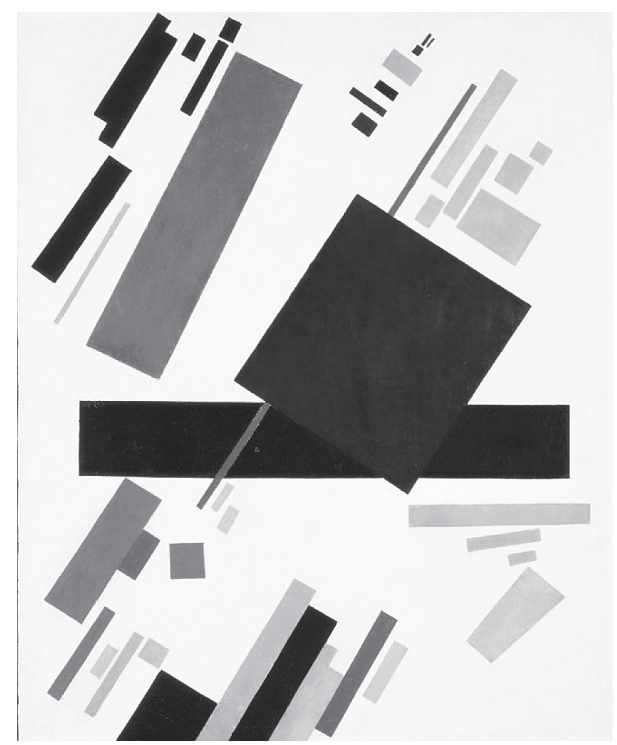

Figura 7: Kasimir Malevich, "Composición suprematista” (rectángulo azul sobre viga púrpura), 1916 (Colección privada)

\section{Referencias}

BADIOU, A. "Fifteen Theses on Contemporary Art". Lacanian ink, Nr. 22, pp. 103-119, 12 Apr. 2003.

. "Pequeño manual de inestética". Buenos Aires: Prometeo Libros, 2009.

BUTLER, J., LACLAU, E., ŽIŽEK, S. "Contingency, Hegemony, Universality: Contemporary dialogues on the Left". Londres: Verso, 2000.

CRONE, R.; MOOS, D. (1991). "Kazimir Malevich, The Climax of Disclosure". Londres: Reaktion Books, 1991. 
DANTO, A. "Embodied Meanings. Critical Essays and Aesthetic Meditations". Nueva York. The Noonday Press, 1994.

."Después del fin del arte: el arte contemporáneo y el linde de la historia".

Traducción al español de Elena Neerman. Barcelona. Paidós Ibérica, 2010.

DRUTT, M. (ed.). "Kazimir Malevich: Suprematism" (32-41). Nueva York: Guggenheim Museum, 2003.

GRUPPI, L. "El concepto de hegemonía en Antonio Gramsci". México: Ediciones de cultura popular, 1978.

GÓMEZ, J. J. (ed.). "Crítica, tendencia y propaganda. Textos sobre arte y comunismo". Traducciones al español de Juan José Gómez, Teresa Muñoz, Juan Pablo Larreta, Miguel Albi y Víctor Borrero. Sevilla: Doble J, 2008.

GRAMSCI, A. (1929-1935) “Quaderni del carcere”. Turín: Einaudi, 1975.

. (1929-1935) "Letteratura e vita nazionale". Turín: Einaudi, 1954.

GROYS, B. "Becoming Revolutionary. On Kazimir Malevich". e-flux journal, Nr. 47, 2013. Disponible en http://worker01.e-flux.com/pdf/article_8972051.pdf.

. "The Weak Universalism". e-flux journal, Nr. 15, 2010. Disponible en http:// worker01.e-flux.com/pdf/article_130.pdf.

HARRISON, CH., WOOD, P. (eds.). "Art in Theory 1900-2000: An Anthology of Changing Ideas". Oxford: Blackwell Publishing, 2003.

HERNÁNDEZ-NAVARRO, M. Á. "El cero de las formas. El cuadrado negro y la reducción de lo visible". Imafronte, Nr. 19-20, pp. 119-140, 2007-2008.

JAKOVLJECIC, B. "Unframe Malevich! Inefability and Sublimity in Suprematism". Art Journal, Vol. 63, Nr. 3, pp. 18-31, otoño 2004.

LEF (1923). "Programa de LEF". pp. 12-22. En: GÓMEZ, J.J. (ed.). Crítica, tendencia y propaganda. Textos sobre arte y comunismo. Traducción al español de Teresa Muñoz. Sevilla: Doble J, 2008.

LEVINGER, E. "Kazimir Malevich on Vision and Sensation". Word \& Image, Vol. 21, Nr. 1, pp. 79-89, enero-marzo 2005.

LISSITZKY, E. (1925) “A. and Pangeometry”. pp. 317-321. En: HARRISON, CH., WOOD, P. (eds.). Art in Theory 1900-2000: An Anthology of Changing Ideas. Oxford: Blackwell Publishing, 2003.

LUECKING, S. "A Man and His Square: Kasimir Malevich and the Visualization of the Fourth Dimension". Journal of Mathematics and the Arts, Vol. 4, Nr. 2, 2010, pp. 87-100.

MALEVICH, K. S., MORAZA, J. L. (1935). "Culto al eclipse (meditaciones de Malevich en su lecho de muerte) Recogidas por Juan Luis Moraza". Revista de Occidente, Nr. 165, pp. 77-92, 1995.

MALEVICH, K. S. (1915). "From Cubism and Futurism to Suprematism: The New Realism in Painting", pp. 173-183. En: HARRISON, CH., P. WOOD, P. (eds). Art in Theory 1900-2000: An Anthology of Changing Ideas. Oxford: Blackwell Publishing, 2003. 
. (1920). "The Question of Imitative Art", pp. 293-298. En: HARRISON, CH, P., WOOD, P. (eds). Art in Theory 1900-2000: An Anthology of Changing Ideas. Oxford: Blackwell Publishing, 2003.

. (1927). "El mundo no objetivo". Traducción al español de Juan Pablo Larreta. Aracena: Gegner, 2013.

MARCADÉ, J. C. "Malevich Panting and Writing: On the Development of a Suprematist Philosophy", pp. 32-41. En: DRUTT, M. (ed.). Kazimir Malevich: Suprematism. Nueva York: Guggenheim Museum, 2003.

MARINETTI, F. T. "Manifesto tecnico della letteratura futurista". Direzione del Movimento Futurista: Milán, 11/05/1912.

TOSCANO, A. "The Sensuous Religion of the Multitude: Art and Abstraction in Negri”. Third Text, Vol. 23, Nr. 4, pp. 369-382, 2009. 